\title{
Growing lettuce under multispectral light-emitting diodes lamps with adjustable light intensity
}

\author{
Giacomo Tosti, ${ }^{1}$ Paolo Benincasa, ${ }^{1}$ Rossano Cortona, ${ }^{1}$ Beatrice Falcinelli, ${ }^{1}$ Michela Farneselli, ${ }^{1}$ \\ Marcello Guiducci, ${ }^{1}$ Andrea Onofri, ${ }^{1}$ Euro Pannacci, ${ }^{1}$ Francesco Tei, ${ }^{1}$ Mario Giulietti ${ }^{2}$ \\ ${ }^{1}$ Department of Agricultural, Food and Environmental Sciences, University of Perugia; \\ ${ }^{2}$ GNC s.r.l., Bastia Umbra (PG), Italy
}

\begin{abstract}
Light-emitting diodes (LEDs) technology offers vast possibilities in plant lighting due to its ability to mix different light frequencies, high energy use efficiency and low heat production combined to long lifespan. In particular, the combined effect of the Blue:Red (B:R) ratio and other frequencies in the central part of the PAR spectrum (CGA, i.e. cyan, green and amber) may be very important, though literature information is scarce. In this paper, the effects of six light spectra from LED technology were tested, i.e.: i) $\mathrm{B}: \mathrm{R}=0.82$ (i.e. similar to sunlight) with CGA (treatment $\mathrm{T} 0)$; ii) $\mathrm{B}: \mathrm{R}=0.82$ without $\mathrm{CGA}$ (T1); iii) red prevalence $(B: R=0.25)$ without $C G A(T 2)$; iv) blue prevalence $(B: R=4)$ without CGA (T3); v) red prevalence with CGA (T4); and vi) blue prevalence with CGA (T5). The experiment was carried out in a walk-in climatic chamber with controlled temperature and relative humidity and an incident PAR photon flux density (PFD) of 300 $\mu \mathrm{mol} \mathrm{m}{ }^{-2} \mathrm{~s}^{-1}$ (14/10 light/dark photoperiod), generated by multispectral LED lamps with adjustable light intensity. Smooth leaved lettuce (Lactuca sativa L. cv Gentilina) was used as the test plant
\end{abstract}

Correspondence: Giacomo Tosti, Department of Agricultural, Food and Environmental Sciences (DSA3), University of Perugia, Perugia, Italy. E-mail: giacomo.tosti@gmail.com

Key words: Blue:Red; PAR spectrum; radiation use efficiency; LAI; energy-biomass conversion efficiency.

Acknowledgements: we would like to thank GNC for the technical help given in the lamp assembly process and for partial funding of the research activities. Finally, this study would not have been possible without technical assistance from Mr. Silvano Locchi and Dr. Riccardo Pandolfi.

Conference presentation: SIA XLV Congress, Sassari, 2016.

Received for publication: 30 November 2017

Revision received: 17 July 2017.

Accepted for publication: 18 July 2017.

(C) Copyright G. Tosti et al., 2018

Licensee PAGEPress, Italy

Italian Journal of Agronomy 2018; 13:883

doi:10.4081/ija.2017.883

This article is distributed under the terms of the Creative Commons Attribution Noncommercial License (by-nc 4.0) which permits any noncommercial use, distribution, and reproduction in any medium, provided the original author(s) and source are credited. and biomass yield (DW, $\mathrm{g} \mathrm{m}^{-2}$ ), LAI, soil coverage proportion (SC\%), energy-biomass conversion efficiency (E-BCE, $\mathrm{kWh} \mathrm{g}^{-1}$ ) and radiation use efficiency (RUE, $\mathrm{g} \mathrm{mol}^{-1}$ photons) were determined. Treatments with red predominance (T2 and T4) showed the highest $\mathrm{SC} \%$ rates, while those with blue predominance (T3 and T5) showed the lowest. Light spectrum also affected leaf size (i.e. mean leaf area). The highest DW and RUE were observed in $\mathrm{T} 2$ and $\mathrm{T} 4$, followed by $\mathrm{T} 0$, while biomass in $\mathrm{T} 3$ and $\mathrm{T} 5$ was significantly lower (similar to T1). LAI values were generally high, but treatments with blue predominance showed the lowest LAI values (both with or without CGA). The introduction of intermediate wavelengths (green, cyan and amber) did not bring about significant improvement in DW or RUE, but resulted in reduced energy-biomass conversion efficiency, mainly due to lower architectural efficiency of the CGA LEDs. Future research should clarify how to optimise the light spectra according to the crop growth phases. The adoption of spectra promoting fast growth is fundamental in the early growth, while the use of spectra maximising yield quality may be more important later on.

\section{Introduction}

In agriculture the term artificial lighting refers to the amount of light that activates, maintains or supports photosynthetic activities or other metabolic processes in protected environments, where incident solar radiation is lacking or inadequate to crop requirements (Bergstrand and Schussler, 2013). In this respect, lamps have continuously evolved over time, from the filament to the gas discharge types (in mercury and then in sodium vapours). In recent years, lamps based on light-emitting diode (LED) technology have become increasingly important (Schubert and Kim, 2005), thanks to their longer lifespan and lower energy consumption (Bian et al., 2015), as compared to other lamps, although they need higher initial investments. For instance, many researches showed how LED lighting may be a reliable option for growing food plants in space (Massa et al., 2007); furthermore, LED lighting is fundamental for indoor gardening, vegetable or spice selfproduction or, on a larger scale, urban vertical farming and other practises, which represent compelling trends in several countries (Van Den Berg and Custers, 2011; Eigenbrod and Gruda, 2015).

Research about LED lighting in crop science has been mainly focused on two strongly interconnected aspects: energetic efficiency as well as quality and intensity of the emitting spectra. It is clear that a LED lighting system is much more efficient than an incandescent lighting system: Wheeler (1992) and Wheeler et al. (1996) showed that a closed plant-production system with incandescent lighting used 1 to $10 \mathrm{~kW} \mathrm{~m}^{-2}$ of electrical power, while a system with HPS lamps used $2.1 \mathrm{~kW} \mathrm{~m}^{-2}$, which translated into 
$4.7 \mathrm{kWh} \mathrm{g}^{-1}$ for lettuce crop production (Wheeler et al., 2008). More recently, using an intra-canopy LED system to grow cowpea crop stands in a controlled environment, Massa et al. (2005) were able to reduce power density to $0.83 \mathrm{~kW} \mathrm{~m}^{-2}$ which corresponds to $1.02 \mathrm{kWh} \mathrm{g}^{-1}$ of dry biomass.

Energy consumption is also related to the emitting spectrum; in this respect, LED lamps may be assembled to produce light in very specific bands of the spectrum and, therefore, they offer wide possibilities to match the requirements of photosynthetic processes and/or non-photosynthetic photoreceptors (Ballare et al., 1991; Domurath et al., 2012).

Recently, several studies have focused on the effect of the blue:red (B:R) ratio on growth, power consumption and organoleptic characteristics of different species (Sebzalian et al., 2014; Piovene et al., 2015). These studies confirmed that the B:R ratio is of fundamental importance for plant growth and development, although other frequencies in the central part of the PAR spectrum (i.e. $500 \leq 1 \leq 600 \mathrm{~nm}$ ) may also play a relevant role, but this aspect has not been yet fully clarified in literature.

One further aspect that deserves attention is that, in spite of an increasing number of detailed studies on plant physiology and photosynthesis pathways in response to light spectrum, only very few of them were performed at a crop level, rather than at an individual plant level. Therefore, useful information about crop production systems is still limited.

On this background, an experiment in controlled environment was conducted at the research facility of the Department of Agricultural, Food and Environmental Sciences (University of Perugia, Italy), aimed at testing the effects of six light spectra on: biomass accumulation, leaf coverage evolution, leaf size and energy-biomass conversion efficiency in a smooth leaved lettuce (Lactuca sativa L., cv Gentilina) crop.

\section{Materials and methods}

\section{The DSA3-lamp}

The LED lighting system was designed and built by the Technical Unit of the Agronomy and Field Crop Division of the Department of Agricultural, Food and Environmental Sciences of the University of Perugia (Italy) in collaboration with the cutting edge company GNC s.r.1.. This system is based on the Luxeon Rebel LED light source from Philips Lumileds ${ }^{\odot}$, and each lamp (DSA3-lamp) contains seven types of LED, which are able to generate seven different frequencies. These seven types (with main peak emissivity) are: royal blue $\left(\lambda_{\text {peak }}=448 \mathrm{~nm}\right)$, blue $\left(\lambda_{\text {peak }}=470\right.$ $\mathrm{nm})$, cyan $\left(\lambda_{\text {peak }}=505 \mathrm{~nm}\right)$, green $\left(\lambda_{\text {peak }}=530 \mathrm{~nm}\right)$, amber $\left(\lambda_{\text {peak }}=\right.$ $590 \mathrm{~nm})$, red $\left(\lambda_{\text {peak }}=627 \mathrm{~nm}\right)$, deep red $\left(\lambda_{\text {peak }}=655 \mathrm{~nm}\right)$ (Figure 1$)$. The overall maximum power of each lamp is $90 \mathrm{~W}$.

The DSA3-lamp emits a pulsed light for each wavelength modulated by individual switching power supplies mounted on board. These feeders are controlled in duty cycle by a microprocessor and they can be singularly tuned (steps of 1 from 0 to $100 \%$ of emitted photon flux intensity). Each LED unit mounted a $60^{\circ}$ lens that guarantees a very good light uniformity at $30 \mathrm{~cm}$ from the lamp. The LEDs are placed on a printed circuit attached to an aluminium support and the circuit is fixed to a forced air cooler and an interposed thermic pad ensures the maintenance of the optimum operating temperature (Figure 2). Differently from other lamps based on LED arrays, the DSA3-lamp, with its 7 adjustable wavelengths, represents a unique and flexible facility that can be used to test a very large number of research questions concerning several aspects of light effect on crop growth.

\section{The growing chamber}

The experiment was carried out in a walk-in climatic chamber $(2 \times 1.5 \times 2.5 \mathrm{~m})$ where temperature and relative humidity were constantly monitored and controlled $\left(20 \pm 1{ }^{\circ} \mathrm{C}\right.$ and $70 \pm 5 \%$, respectively). In order to avoid any undesired light, the climatic chamber was placed in a building with no windows and all the inner surfaces of the chamber were painted in opaque black; moreover a black ceiling was interposed between the inner part and the chamber entrance door. The chamber contains 18 DSA3-lamps disposed on three shelves, each divided into 6 compartments separated by reflecting shields in order to avoid any light interference among the lamps. During the experiment, each lamp provided a constant incident PAR photon flux density (PFD) of $300 \mu \mathrm{mol} \mathrm{m}^{-2} \mathrm{~s}^{-1}$ with a $14 \mathrm{~h} / 10 \mathrm{~h}$ light/dark photoperiod.

\section{Crop management}

The experiment was conducted using smooth blonde lettuce (Lactuca sativa L., cultivar Gentilina). Plants were sown on 04 December 2015 in plastic trays $(35.5 \times 21.5 \times 4 \mathrm{~cm})$ by using a vacuum drill, on a hexagonal pattern at 952 plants $\mathrm{m}^{-2}$ density. Flawed seedlings were replaced immediately after emergence (three days after seeding). Quartz sand was used as the growth substrate (4 $\mathrm{kg}$ per tray) and seeds were covered with $40 \mathrm{~g}$ of vermiculite. Open

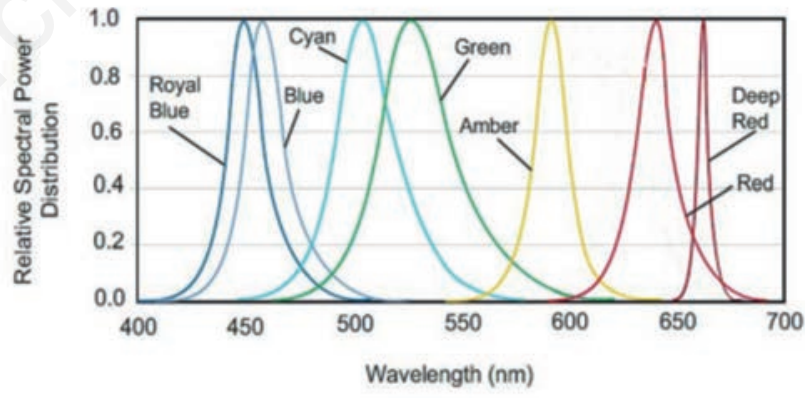

Figure 1. Relative spectral power distribution of the seven light frequencies available on the DSA3-lamp. Adapted from www.lumileds.com.

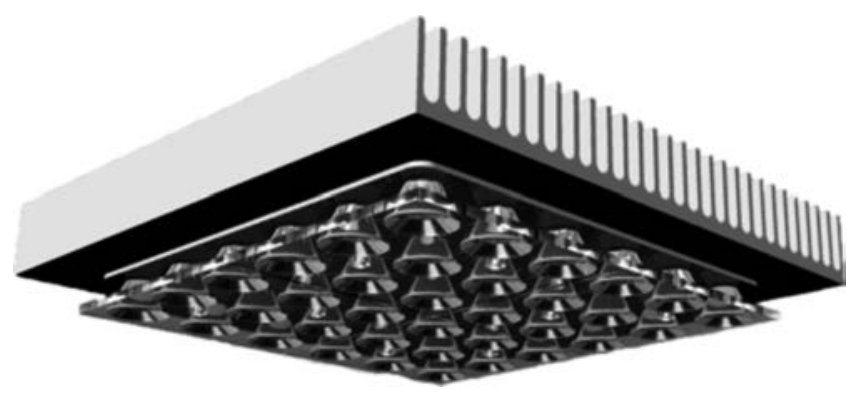

Figure 2. 3-D image of the DSA3-lamp, in detail: the aluminium radiator for support and cooling purposes connected, through the thermic pad, to the circuit plate where the single LED are slotted in. 
cycle sub-irrigation was used to avoid any risk of plant disease due to the nutrient solution recirculation and/or leaf wetting. Irrigation was performed every $3^{\text {rd }}$ day by using $1.5 \mathrm{~L}$ of nutrient solution per tray, consisting of $1.0 \mathrm{~g} \mathrm{~L}^{-1}$ of Flory $9 \mathrm{Hydro}^{\odot}(\mathrm{N}: \mathrm{P}: \mathrm{K}=15: 7: 22$; $\mathrm{MgO}=6 \%$; micronutrients: $\mathrm{B}=0.03 \%, \mathrm{Co}=0.002 \%, \mathrm{Cu}=0.002 \%$, $\mathrm{Mo}=0.005 \%, \mathrm{Zn}=0.01 \%$ ) and $0,03 \mathrm{~g} \mathrm{~L}^{-1}$ of Sequestrene NK138 $(\mathrm{Fe}$ chelate $=6 \%)$. For the first irrigation a half dose was used in order to prevent an excessive accumulation of salts within the substrate that could adversely affect the emergence (Pace et al., 2012). The lettuce was harvested the 07 January 2016 i.e. 31 days after emergence (DAE).

\section{Light treatments and experimental design}

Three $\mathrm{B}: \mathrm{R}$ ratios (i.e. similar to sunlight $\mathrm{B}: \mathrm{R}=0.82$, red prevalence $B: R=0.25$ and blue prevalence $B: R=4$ ) and presence/absence of cyan, green and amber frequencies (CGA frequencies, representing the central part of the PAR spectrum) were combined in six treatments (Figure 3 ) and compared in a randomised block design with three replicated trays per treatment (one lamp per tray). In detail, the six treatments were composed by: i) $\mathrm{B}: \mathrm{R}=0.82$ (i.e. similar to sunlight) with CGA (treatment T0); ii) $\mathrm{B}: \mathrm{R}=0.82$ without CGA (T1); iii) red prevalence ( $\mathrm{B}: \mathrm{R}=0.25)$ without CGA (T2); iv) blue prevalence $(\mathrm{B}: \mathrm{R}=4)$ without $\mathrm{CGA}(\mathrm{T} 3)$; v) red prevalence with CGA (T4); and vi) blue prevalence with CGA (T5). The overall incident PAR photon flux density (PFD) was $300 \mu \mathrm{mol} \mathrm{m} \mathrm{m}^{-2} \mathrm{~s}^{-1}$ in each treatment, therefore light treatments differed in terms of both wavelength distribution and irradiance for each frequency (Figure 3).

\section{Measurements}

Soil coverage proportion ( $\mathrm{SC} \%$ ) was recorded from 1 to 23 days after emergence (DAE) via image analysis. The pictures were taken daily and processed via image software analysis using imaging crop response analyser (ICRA; Rasmussen et al., 2007). In order to maintain the result series as consistent as possible across time, pictures were taken with the same camera (ASUS, 8.0 megapixel) adopting the same framing and distance. Before being processed, pictures were cut to isolate the central part of the image (maximum homogeneity of the canopy) and then corrected for brightness and contrast. On the basis of these measures the $\mathrm{SC} \%$ curves were composed for each experimental unit. Soil coverage was used to estimate the daily crop absorbed radiation (Qa) as:

$$
\mathrm{Q}_{\mathrm{a}}=\mathrm{Q}_{\mathrm{i}} \frac{\mathrm{sC} \%}{100}(1-a)
$$

where Qi is the daily incident radiation $\left(\mathrm{mol} \mathrm{m}^{-2} \mathrm{~s}^{-1}\right), \mathrm{SC} \%$ is the percentage of area covered by the canopy, and $a$ represents the albedo. As the photoperiod and the daily incident radiation were the same for all treatments and throughout the whole crop cycle (i.e. $14 \mathrm{~h}$ light and $10 \mathrm{~h}$ dark and $300 \mu \mathrm{mol} \mathrm{m}^{-2} \mathrm{~s}^{-1}$, respectively) the daily Qi was $15.12 \mathrm{~mol} \mathrm{~m}^{-2} \mathrm{~d}^{-1}$. Albedo was measured using a quantum PAR sensor formed by a non-shielded GASP (phosphogallium arsenide) photodiode (G1116, Hamamatsu Photonics K.K.). The measurements were performed when SC\% reached 100 (i.e. canopy closure). As the spectral sensitivity of the GASP sensor is not uniform within the PAR region, $a$ was estimated as the ratio between the light reflected from a mirror placed at the top of the canopy (i.e. a surface with $a=1$ ) and the light reflected from the canopy itself.

At 31 DAE biomass was sampled from the core portion of each tray and dry weight accumulation was determined. Leaf area of a subsample of three representative plants per plot was determined by using ICRA (Rasmussen et al., 2007) and LAI was then calculated referring to the whole sample weight. Radiation use efficiency (RUE, $\mathrm{g} \mathrm{mol}^{-1}$ photons) was calculated as the ratio between accumulated biomass (DW, $\mathrm{g} \mathrm{m}^{-2}$ ) and cumulated Qa at the end of growing cycle.

The electric power $(\mathrm{C}, \mathrm{W})$ absorbed by each lamp was quantified by measuring the applied potential difference and the electric current intensity downstream of the switching power supply, using a precision multimeter. After determining $\mathrm{C}$, it was possible to calculate the energy-biomass conversion efficiency (E-BCE, $\mathrm{kWh} \mathrm{g}^{-1}$ ), i.e. the electrical energy used for one unit of dry matter production (Poulet et al., 2014).

\section{Data analysis}

The soil coverage dynamics were described by adopting a four parameter Weibull type II model in order to estimate the inflection point for each treatment. Model parameters were estimated by using the drc package (Ritz et al., 2015) of the R statistical software (R Development Core Team, 2016). Data at final sampling were subjected to analysis of variance and means were separated by Fisher's protected least significant difference (LSD) at $\mathrm{P}=0.05$ probability level.

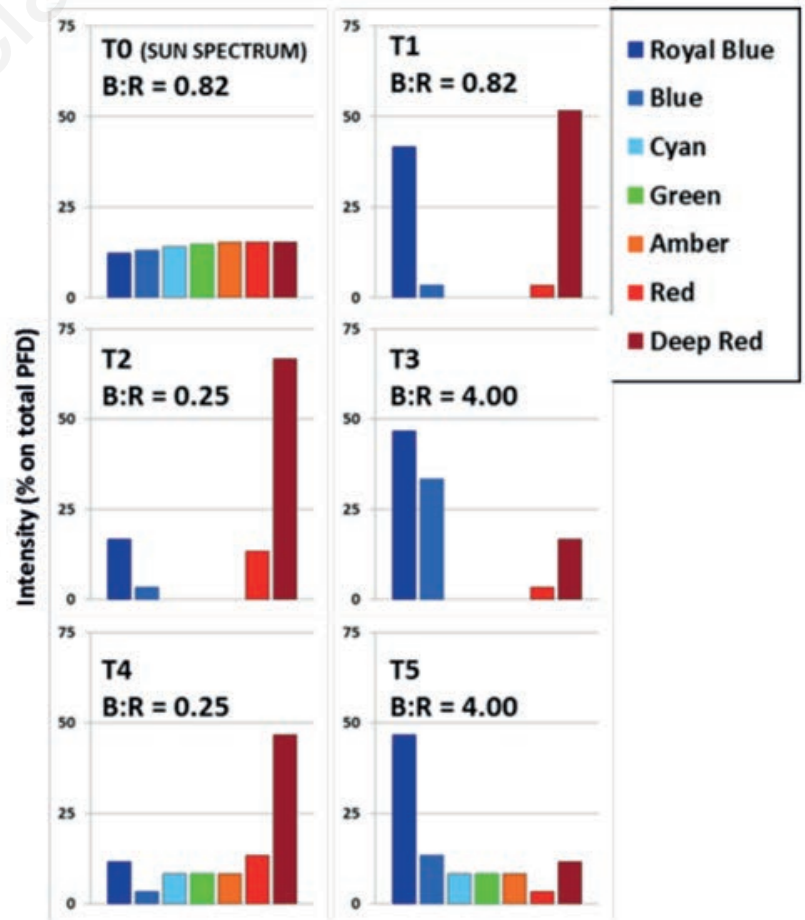

Figure 3. Intensity of each wavelength relative to the total photon flux density (\%) in the six light treatments: (i) $\mathrm{B}: \mathrm{R}=0.82$ (i.e. similar to sunlight) with CGA (treatment T0), (ii) $B: R=0.82$ without CGA(T1), (iii) red prevalence $(B: R=0.25)$ without CGA (T2), (iv) blue prevalence (B:R = 4) without CGA (T3), (v) red prevalence with CGA (T4) and (vi) blue prevalence with CGA (T5). The lamps provided a constant incident PAR photon flux density (PFD) of $300 \mu \mathrm{mol} \mathrm{m} \mathrm{m}^{-2} \mathrm{~s}^{-1}$, and a photoperiod of $14 \mathrm{light} /$ 10 dark hours. 


\section{Results}

After emergence, the $\mathrm{SC} \%$ rates observed in the six treatments were largely different (Figure 4). Treatments with red predominance (T2 and T4) showed the highest values, while those with blue predominance (T3 and T5) the lowest, so the canopy closure in T2 and T4 was achieved four days before T3 and T5 (Figure 4). The end of exponential growth was achieved at 10 (T0, T2 and T4), 11 (T1 and T5) and 12 DAE (T3).

Beside SC\%, light spectrum also affected leaf size, as mean leaf area was reduced by blue light (Figure 5), while specific leaf area (SLA) was not affected by treatments in this study (range from 37.0 to $41.0 \mathrm{~cm}^{2} \mathrm{~g}^{-1}$ ). The highest biomass accumulation was observed in T2 and T4 (Table 1), followed by T0, while biomass in T3 and T5 was significantly lower (similar to T1). LAI was generally high, but treatments with blue predominance showed the lowest values (both with or without CGA); while CGA frequencies increased LAI values in the treatment with red predominance (Table 1).

Cumulated Qa was the highest in T2 and T4 (similar to T0), while T3 and T5 reached lower values (not different from T1). RUE was the highest in T2 and T4, intermediate in T0 and low in T1, T3 and T5; so a high PFD of blue light reduced both cumulated Qa and RUE.

The best treatment in terms of E-BCE was T2 that showed the lowest value, followed by control T1. The most energy-consuming treatments were $\mathrm{T} 0$ and $\mathrm{T} 5$ while $\mathrm{T} 3$ and $\mathrm{T} 4$ were on an intermediate level (Table 1).

\section{Discussion}

The effect of light spectrum on soil cover was the most important leading force for crop biomass accumulation and soil cover was negatively influenced by the predominance of blue light (Figure 4). On the other hand, as confirmed by other researches (Olle and Virsile, 2013), long wavelength radiation (i.e. red) exerted a positive effect on cellular distension (resulting in increased leaf expansion rate and LAI). The higher was the proportion of blue light on total PFD, the longer (i.e. slower) was the initial growth phase (Figure 4). This happened because the onset of leaf overlapping between neighbour plants took place later in slow expanding leaves (T3, T5 and T1) as compared to fast expanding ones (T0, T2 and T4). Our results are in line with the trend found by Dougher and Bugbee (2001) that leaf expansion (and LAI) of lettuce decreases with increasing blue light. However, there are several studies where white light and blue light were found to be the most efficient for plant growth (Hoenecke et al., 1992; Bergstrand et al., 2012; Fan et al., 2013; Poulet et al., 2014). For instance, there is scientific evidence that blue light can be an effective stimulus for fruit yield and quality improvement as well as for disease resistance (Xu et al., 2012). Clearly, plant response to dif-

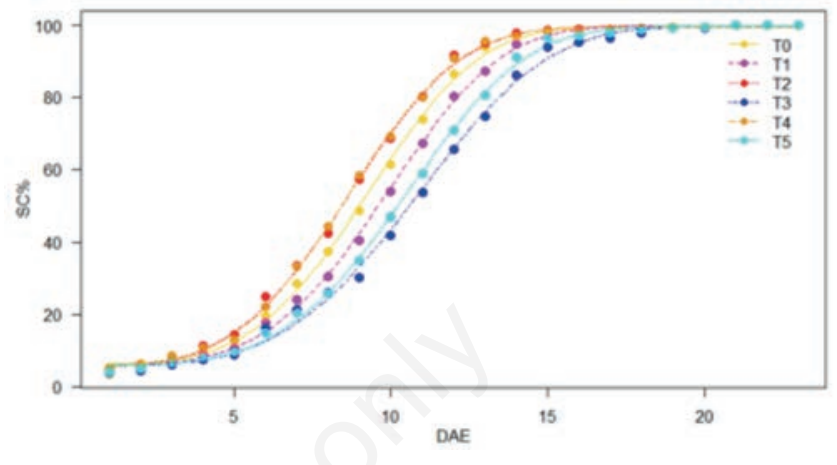

Figure 4. Soil cover proportion (SC, \%) during lettuce growth cycle (expressed as days after emergence, DAE) in the six light treatments (codes are in Figure 3).

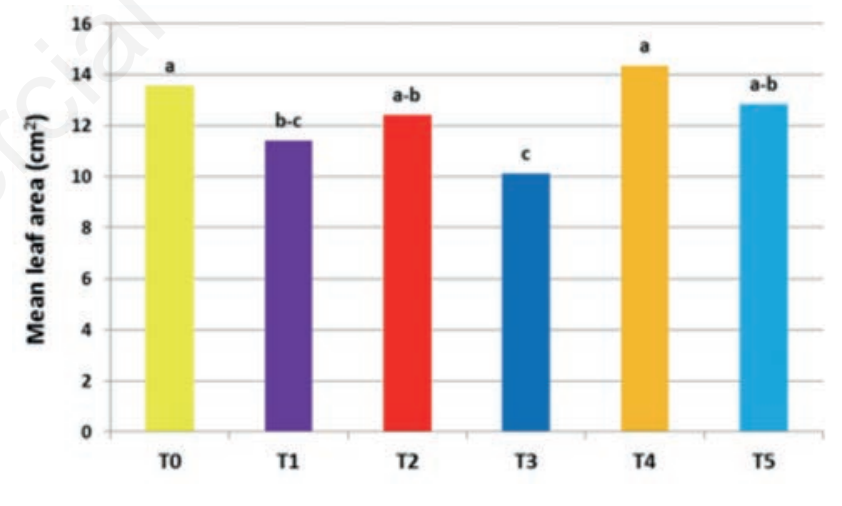

Figure 5. Mean leaf area $\left(\mathrm{cm}^{2}\right)$ observed at final sampling date in the six light treatments (codes are in Figure 3). Means followed by different letters are significantly different at $\mathbf{P}<\mathbf{0 . 0 5}$ (Fisher's LSD).

Table 1. Biomass accumulation (Biomass, $\mathrm{g} \mathrm{m}^{-2}$ ), Leaf Area Index (LAI), cumulated absorbed radiation (Qa, mol $\left.\mathrm{m}^{-2}\right)$, Radiation Use Efficiency (RUE, $\mathrm{g} \mathrm{mol}^{-1}$ ) and Energy-Biomass Conversion Efficiency (E-BCE, $\mathrm{kWh} \mathrm{g}^{-1}$ ) recorded at final sampling date in the six light treatments (codes are in Figure 3). Means followed by different letters within a column are significantly different at $\mathrm{P}<0.05$ (Fisher's LSD).

\begin{tabular}{|c|c|c|c|c|c|}
\hline & Biomass $\left(\mathrm{g} \mathrm{m}^{-2}\right)$ & LAI & Cumulated $\mathrm{Qa}\left(\mathrm{mol} \mathrm{m}^{-2}\right)$ & RUE (g mol $\left.{ }^{-1}\right)$ & E-BCE $\left(\mathrm{kWh} \mathrm{g}^{-2}\right)$ \\
\hline T0 (SUN) & $207^{\mathrm{b}}$ & $9.58^{\mathrm{ab}}$ & $287^{a b}$ & $0.722^{b}$ & $1.96^{\mathrm{a}}$ \\
\hline $\mathrm{T} 1$ & $183^{c}$ & $8.06^{\mathrm{c}}$ & $279^{b c}$ & $0.656^{c}$ & $1.17^{\mathrm{c}}$ \\
\hline $\mathrm{T} 2$ & $231^{\mathrm{a}}$ & $8.71^{\mathrm{bc}}$ & $296^{\mathrm{a}}$ & $0.779 \mathrm{a}$ & $0.97^{\mathrm{d}}$ \\
\hline T3 & $168^{c}$ & $7.64^{\mathrm{c}}$ & $265^{\mathrm{d}}$ & $0.635^{\mathrm{c}}$ & $1.56^{\mathrm{b}}$ \\
\hline $\mathrm{T} 4$ & $217^{\mathrm{ab}}$ & $10.26^{\mathrm{a}}$ & $286^{\mathrm{ab}}$ & $0.760^{\mathrm{ab}}$ & $1.41^{\mathrm{b}}$ \\
\hline $\mathrm{T} 5$ & $180^{c}$ & $7.89^{\mathrm{c}}$ & $272^{\mathrm{cd}}$ & $0.663^{\mathrm{c}}$ & $1.86^{\mathrm{a}}$ \\
\hline SEM & 5.3 & 0.450 & 3.6 & 0.0157 & 0.057 \\
\hline
\end{tabular}

SEM: standard error of a mean 
ferent wavelengths (and different wavelength ratios) is mainly dependent on plant species (Bergstrand et al., 2014).

Our experiment confirms that dry biomass accumulation and leaf size were clearly related to the imposed spectrum (Figure 5; Table 1); however, our results point out that beside the B:R ratio, also CGA wavelengths can affect such feature in lettuce plants. All treatments including these wavelengths performed better than the homologues without CGA (T0>T1, T4>T2 and T5>T3). Therefore, since the phyillochron was constant across treatments (data not shown), LAI at final sampling was also increased by the presence of CGA (Table 1). As observed by other researchers, even if red and blue light are basal in the lighting spectra for all the species, unprofitable spectral parts as green or yellow also have significant physiological effects (Domurath et al., 2012; Olle and Virsile, 2013). As the PFD was maintained constant during the whole experiment (i.e. $300 \mu \mathrm{mol} \mathrm{m} \mathrm{m}^{-2} \mathrm{~s}^{-1}$ ) and albedo accounted for less than $2 \%$ of incident PFD (data not shown), Qa was mainly influenced by $\mathrm{SC} \%$. As a consequence, treatments with high $\mathrm{SC} \%$ rates reached the highest value of cumulated Qa (Table 1).

Concerning the radiation use efficiency, our findings are in line with those of other researches where B:R of 1:7 was the best light combination to increase leaf chlorophyll $(\mathrm{a}+\mathrm{b})$ content and net photosynthetic rate, as well as plant growth (Chen et al., 2004). Beside the relative $B: R$ ratio, the overall PFD of blue radiation represents a crucial information that should be made available to allow an unambiguous interpretation of the results. Indeed, T1 and T0 are characterised by the same B:R, but the latter treatment showed a higher RUE value, due to the presence of CGA and consequent lower amount of blue PFD (Table 1; Figure 3).

In general, E-BCE for each light treatment is determined by both total dry biomass accumulation and energy consumption and, due to architectural reasons, red and blue LEDs have higher energetic efficiency as compared to CGA LED. This may explain why treatments with same B:R ratio, showed reduced E-BCE depending on the presence of CGA. Indeed, the slightly better performance in terms of biomass (T0 vs T1) or cumulated Qa (T5 vs T3) was impaired by the highest energy consumption of CGA LEDs (Table 1).

As stated by other researchers (Massa et al., 2015), another crucial point to improve lighting efficiency could be represented by a detailed and full understanding of the light transmission through the canopy at single wavelength scale. This represents an essential prerequisite to create species-specific light 'recipes' that are able to minimize the energy consumption while maintaining crop growth and quality in controlled environment.

\section{Conclusions}

Under a constant incident photon flux density, lettuce reacted differently under different light spectra. High proportion of red light (627-655 nm) increased crop growth, leaf expansion and RUE, while an increase of the blue light proportion reduced biomass accumulation via both low leaf expansion and reduced RUE.

The introduction of intermediate wavelengths (green, cyan and amber) did not bring to significant improvement in biomass accumulation and RUE, but resulted in reduced energy-biomass conversion efficiency, mainly due to lower architectural efficiency of the CGA LEDs. The use of these intermediate wavelengths, that are very important for quality and organoleptic features, should therefore be limited to the cases where one is not primarily inter- ested in the energy-biomass conversion efficiency.

Future research should clarify how to optimise the light spectra according to the crop growth phases. Indeed, it might be expected that the adoption of spectra promoting fast growth is fundamental in the early growth phases to maximise radiation use efficiency, while the use of spectra maximising yield quality may be more important later on.

\section{References}

Ballare C, Scopel A, Sanchez R, 1991. On the opportunity cost of the photosynthate invested in stem elongation reactions mediated by phytochrome. Oecologia 86:561-7.

Bergstrand K, Asp H, Schussler HK, 2014. Development and acclimatisation of horticultural plants subjected to narrow-band lighting. Eur. J. Hortic. Sci. 79:45-51.

Bergstrand K, Schussler HK, 2012. Recent progresses on the application of LEDs in the horticultural production. In: N. Castilla, O. VanKooten, S. Sase, J.F. Meneses, W.H. Schnitzler, and E. VanOs (Eds.), XXVIII International Horticultural Congress on Science and Horticulture for People (ihc2010): International Symposium on Greenhouse 2010 and Soilless Cultivation, 927:529-34.

Bergstrand K, H Schussler HK, 2013. Growth, development and photosynthesis of some horticultural plants as affected by different supplementary lighting technologies. Eur. J. Hortic. Sci. 78:119-25.

Bian ZH, Yang QC, Liu WK, 2015. Effects of light quality on the accumulation of phytochemicals in vegetables produced in controlled environments: a review. J. Sci. Food Agric. 95:869-77.

Chen M, Chory J, Fankhauser C, 2004. Light signal transduction in higher plants. Annu. Rev. Genet. 38:87-117.

Domurath N, Schroeder FG, Glatzel S, 2012. Light response curves of selected plants under different light conditions. In: S. Hemming and E. Heuvelink (Eds.), VII International Symposium on Light in Horticultural Systems, 956:291-8.

Dougher TA, Bugbee B, 2001. Differences in the response of wheat, soybean and lettuce to reduced blue radiation. Photochem. Photobiol. 73:199-207.

Eigenbrod C, Gruda N, 2015. Urban vegetable for food security in cities. A review. Agron. Sustainable Dev. 35:483-98.

Fan X, Jie Z, Xu Z, Xuelei J, Xiaoying L, Ying G, 2013. Effects of different light spectra on photosynthetic structures and photosynthate of non-heading Chinese cabbage. Res. Crop. 14:555-60.

Hoenecke ME, Bula RJ, Tibbitts TW, 1992. Importance of "blue" photon levels for lettuce seedlings grown under red-light-emitting diodes. Hortsci. 27:427-30.

Massa G, Mitchell C, Emmerich J, Morrow R, 2005. Development of a reconfigurable LED plant-growth lighting system for equivalent system mass reduction in an ALS. SAE Technical Paper 2005-01-2955.

Massa G, Emmerich JC, Morrow RC, Bourget CM, Mitchell CA, 2007. Plant-growth lighting for space life support: a review. Gravit. Space Res. 19:19-30.

Massa G, Graham T, Haire T, Flemming C, Newsham G, Wheeler $\mathrm{R}, 2015$. Light-emitting diode light transmission through leaf tissue of seven different crops. Hortsci. 50:501-6.

Olle M, Virsile A, 2013. The effects of light-emitting diode lighting on greenhouse plant growth and quality. Agric. Food Sci. 22:223-34. 
Ouzounis T, Rosenqvist E, Ottosen CO, 2015. Spectral effects of artificial light on plant physiology and secondary metabolism: A review. Hortsci. 50:1128-35.

Pace R, Benincasa P, Ghanem ME, Quinet M, Lutts S, 2012. Germination of untreated and primed seeds in rapeseed (Brassica napus var Oleifera Del.) under salinity and low matric potential. Exp. Agr. 48:238-51.

Piovene C, Orsini F, Bosi S, Sanoubar R, Bregola V, Dinelli G, Gianquinto G, 2015. Optimal red:blue ratio in led lighting for nutraceutical indoor horticulture. Sci. Hortic. 193:202-8.

Poulet L, Massa G, Morrow RC, Bourget CM, Wheeler RM, Mitchell CA, 2014. Significant reduction in energy for plantgrowth lighting in space using targeted LED lighting and spectral manipulation. Life Sci. Space Res. 2:43-53.

R Core Team, 2016. R: A language and environment for statistical computing. R Foundation for Statistical Computing, Vienna, Austria. Available from: https://www.R-project.org/

Rasmussen J, Nørremark M, Bibby B, 2007. Assessment of leaf cover and crop soil cover in weed harrowing research using digital images. Weed Res. 47:299-310.

Ritz C, Baty F, Streibig JC, Gerhard D, 2015. Dose-response analysis using R. PLoS One 10:e146021.

Sabzalian MR, Heydarizadeh P, Zahedi M, Boroomand A,
Agharokh M, Sahba MR, Schoefs B, 2014. High performance of vegetables, flowers, and medicinal plants in a red-blue LED incubator for indoor plant production. Agron. Sustainable Dev. 34:879-86.

Schubert EF, Kim JK, 2005. Solid-state light sources getting smart. Science 308:1274-8.

Van Den Berg AE, Custers MHG, 2011. Gardening promotes neuroendocrine and affective restoration from stress. J. Health Psychol. 16:3-11.

Wheeler RM, 1992. Gas-exchange measurements using a large, closed plant growth chamber. Hortsci. 27:777-80.

Wheeler RM, Mackowiak CL, Stutte GW, Sager JC, Yorio NC, Ruffe LM, Fortson RE, Dreschel TW, Knott WM, Corey KA, 1996. NASA's biomass production chamber: a testbed for bioregenerative life support studies. Adv. Space Res. 18:21524.

Wheeler RM, Mackowiak CL, Stutte GW, Sager JC, Yorio NC, Ruffe LM, Sager JC, Prince RP, Knott WM, 2008. Crop productivities and radiation use efficiencies for bioregenerative life support. Adv. Space Res. 41:706-13.

Xu H, Xu Q, Li F, Feng Y, Qin F, Fang W, 2012. Applications of xerophytophysiology in plant production-LED blue light as a stimulus improved the tomato crop. Sci. Hortic. 148:190-6. 